\title{
Determining Physical and Mental Health Conditions Present in Older Adult Refugees: A Mini-Review
}

\author{
Caren J. Frost Nathaniel J. Morgan Hayder Allkhenfr Susan Dearden \\ Rebekah Ess Wafi Fawzan Albalawi Allyson Berri L. Scott Benson
}

Lisa H. Gren

Center for Research on Migration \& Refugee Integration, University of Utah, Salt Lake City, UT, USA

\section{Keywords}

Physical health · Mental health · Older adult refugees

\begin{abstract}
In 2017, there were over 65 million displaced persons at the global level, with approximately 23 million of these people living as refugees around the world. In this same year, the US resettled 53,716 refugees, with the State of Utah receiving 954 of those refugees. Refugees, in general, often face health-related challenges upon resettlement. Since the health of aging refugee men and women is of growing concern, host communities face significant challenges in accommodating the health needs of a diverse refugee population. This study, a review of physical and mental health data from the Utah Department of Health, was undertaken in an effort to ascertain the prevalence of health conditions among refugee men and women 60 years and older arriving in Utah. Findings include information on diseases correlated with increasing age, such as hypertension, decreases in vision, arthritis, and low back pain, which are common among this population of refugees aged 60 years and older. Overall,
\end{abstract}

most of the health conditions assessed affect women and men with a similar prevalence. Some notable exceptions are a history of torture and violence, and a propensity for tobacco use. When dealing with refugee men older than 60 years, providers should consider the psychological ramifications of having endured such atrocities, as well as introduction to evidence-based tobacco cessation programs. When working with refugee women of the same age, an increase in the prevalence of musculoskeletal pain and urinary tract infections should be considered.

(c) 2018 S. Karger AG, Basel

\section{Background}

There were over 65 million internationally displaced persons, with approximately 23 million of these people living as refugees around the world, as of 2017 [1]. Fleeing persecution, natural disaster, or conflict, a total of 28,300 people leave their homes every day, adding to an ever-growing refugee crisis [1, 2]. In 2017, the US resettled 53,716 refugees, with the State of Utah receiving 954

\section{KARGER}

(c) 2018 S. Karger AG, Basel

E-Mail karger@karger.com

www.karger.com/ger
Caren J. Frost, PhD, MPH

Center for Research on Migration \& Refugee Integration

University of Utah

Salt Lake City, Utah 84112 (USA)

E-Mail caren.frost@ socwk.utah.edu 
of those refugees; these numbers are decreased from 2016, with 84,994 and 1,418 refugees resettled, respectively $[3,4]$.

Refugees often face health-related challenges upon resettlement. Though some will manifest the difficulties of resettlement with newly appearing health and mental health problems, many arrive in their resettlement countries with preexisting conditions [5-8]. These preexisting conditions, left untreated over time, can progress into additional, more complex, comorbid, difficult-to-treat, expensive, and/or life-threatening conditions.

The Refugee Act of 1980, which created The Federal Refugee Resettlement Program, mandates that each refugee undergo a comprehensive, timely, and culturally sensitive medical screening $[3,9]$. Refugees are especially vulnerable to health-care challenges, such as employment circumstances and access to health care [3]. For example, health-care costs might make it difficult for aging refugees to afford vital medications [10, 11]. Additionally, cultural norms and attitudes can account for critical differences in how health care among refugee populations is perceived.

Furthermore, cultural differences can make discussing mental health issues especially difficult $[11,12]$, despite the fact that mental health conditions in refugees are common. Traumatic events - including those endured during war, having been forced to flee their homelands, and adverse experiences while living in refugee camps put many refugees at higher risk for developing serious mental health disorders. These mental health issues include post-traumatic stress disorder (PTSD), anxiety, and depression [13-15].

Due to unemployment, or underemployment, within the refugee community, both men and women may be forced to work in order to support their families. Due to this shift in gender roles with both men and women working outside the home, many refugee men experience downward mobility. Conversely, many women experience upward mobility and an increase in occupational opportunities once in the US as compared with their country of origin. However, this change of gender roles within the family frequently creates conflict between a refugee's cultural values and those of the host country [16]. These changes in employment status and gender roles can potentially affect access to health care and ultimately impact overall health.

The health of aging refugee men and women is of growing international concern. As the scale of refugee migration continues to grow, host communities face significant challenges in accommodating the health needs of a diverse refugee population [2]. This review was undertaken in an effort to ascertain the prevalence of health conditions among refugee men and women 60 years and older arriving in Utah.

\section{Methods}

\section{Participants and Procedures}

In order to better understand the health needs of the aging refugee population, we analyzed health screening data available from the Utah Department of Health. The dataset included all refugees resettled to Utah from 2012 to 2017 who were at least 60 years of age at the time of arrival. Data for this study come from the Refugee Health Program housed within the Prevention, Treatment and Care Program at Utah Department of Health. These data were initially collected at the domestic refugee health screening, which is completed in accordance with the Centers for Disease Control and Prevention (CDC) guidelines and recommendations for domestic refugee screening [17]. The data are then documented on the Refugee Health Screening Form (RHSF) and sent to the Refugee Health Program for review, documentation, and storage.

The RHSF has both physical and mental health indicators and, for the purposes of reporting our findings, we grouped the indicators based on the physician specialty area under which they fall. For the study, prevalence for each condition was measured as a positive screen on the RHSF, defined as any diagnosis written by the provider; signs or symptoms related to a diagnosis, such as a single instance of elevated blood pressure or a lab value that exceeded the age- and sex-specific normal range; or provider referral for further diagnosis or treatment. The RHS-15 is a validated tool used to assess mental health with 2 scales. The RHS-I score identifies known indicators of PTSD, depression, and anxiety, and a score of 12 or more is defined as positive; the RHS-II score is an indicator of distress, and a score of 5 or more is defined as positive. The overall RHS-15 score is positive if either RHS-I or RHS-II is positive [18].

\section{Demographic Information Assessment}

Demographic data are self-reported and include age and country or ethnicity of origin or culture. Due to an overwhelming number of ethnicities reported, the Utah Department of Health created a categorical variable to combine ethnicities (nativity) that identifies a culture of origin, and these were used for reporting on the RHSF. For the purposes of analysis, we combined all countries/ ethnicities with fewer than 5 reported refugees into a single category.

\section{Statistical Analysis}

Descriptive statistics were calculated for demographic variables. The prevalence for each diagnosis in the RHSF is reported, as well as an overall prevalence of having at least 1 positive diagnosis. $\chi^{2}$ tests were calculated on all dichotomous variables to identify any significant differences between men and women, and we report Fisher's exact $p$ values. Analyses were completed using SAS version 9.4 (SAS Institute, Inc., Cary, NC, USA). 


\section{Results}

Between 2012 and 2017, 7,017 refugees were resettled in Utah. Of these, 217 were aged 60 years and older (118 men [54.4\%], 99 women [45.6\%]). All refugees aged 60 years or older completed the RHSF. During this time period, 5 countries/ethnicities (Iraq, Bhutan, Sudan, Democratic Republic of the Congo, Karen from Myanmar) account for $81 \%$ of all men and $77 \%$ of women studied (Table 1). Women were slightly older than men, as measured by both mean and median ( 68.3 and 67 vs. 67.3 and 65 , respectively), while the range for men was much wider than for women ( 41 vs. 28 years). There was no significant difference in age $(p=0.327)$. The oldest population was that from Bhutan (data not shown).

Of the men and women who resettled to Utah, 198 individuals (91\%) had at least 1 positive screen on the Utah Health Screening Report, with little difference between women and men (Table 2). The most common positive screens for physical health conditions were in the groupings of ophthalmology, cardiology, infectious disease, and musculoskeletal pain. In ophthalmology, 136 individuals $(62.6 \%)$ had a positive screen, of which the majority $(n=97,71.3 \%)$ had a visual acuity score greater than 20/40. In cardiology, 96 individuals $(44.2 \%)$ had a positive screen, of which the majority $(n=73,33.6 \%)$ had hypertension. In infectious disease, the majority of individuals with a positive screen $(n=85,39.2 \%)$ had evidence for the diagnosis of tuberculosis in their record as measured by QuantiFERON-TB Gold or PPD test. No individuals were reported as infected with HIV. Musculoskeletal pain included arthritis $(n=27,12.4 \%)$ and low back pain $(n=33,15.2 \%)$.

Among the mental health indicators, the RHS-I score had the highest prevalence $(n=88,40.6 \%)$ and was indicative of symptoms of PTSD, depression, and/or anxiety. Diagnosable depression, however, had only 10 confirmed instances in men (8.5\%) and 13 confirmed instances in women $(13.1 \%)$.

Most conditions had a similar prevalence between men and women, with only 2 categories having statistically significant findings. The first was prevalence of torture (13.6\% for men vs. $5.1 \%$ for women, $p=0.039)$; the second was prevalence of musculoskeletal pain (21.2\% for men vs. $34.3 \%$ for women, $p=0.033$ ).

Notable exceptions exist, including those falling under the specialty of ear, nose, and throat (19.5\% for men vs. $12.1 \%$ for women) and individuals with corneal opacity (10 men and 5 women). Men were also reported to smoke slightly more; 6 men claimed tobacco use, with only 1

Determining Physical and Mental Health

Conditions in Older Adult Refugees
Table 1. Demographic information on refugee men and women aged 60 years and older arriving in Utah between 2012 and 2017

\begin{tabular}{|c|c|c|}
\hline \multirow[t]{2}{*}{ Characteristics } & \multicolumn{2}{|c|}{ Arrivals by gender } \\
\hline & $\begin{array}{l}\text { Men } \\
(n=118)\end{array}$ & $\begin{array}{l}\text { Women } \\
(n=99)\end{array}$ \\
\hline \multicolumn{3}{|l|}{ Country/ethnicity of origin, $n(\%)^{\mathrm{a}}$} \\
\hline Afghanistan & $1(0.8)$ & $4(4.0)$ \\
\hline Bhutan & $21(17.8)$ & $14(14.1)$ \\
\hline Cuba & $4(3.4)$ & $3(3.0)$ \\
\hline Democratic Republic of the Congo & $11(9.3)$ & $12(12.1)$ \\
\hline Iran & $4(3.4)$ & $5(5.0)$ \\
\hline Iraq & $36(30.5)$ & $30(30.3)$ \\
\hline Karen (from Myanmar) & $11(9.3)$ & $9(9.1)$ \\
\hline Somalia & $8(6.8)$ & $9(9.1)$ \\
\hline Sudan & $6(5.1)$ & $2(2.0)$ \\
\hline $\begin{array}{l}\text { Country/ethnicity }<5 \text { total } \\
\quad \text { arrivals, } n(\%)^{\mathrm{b}}\end{array}$ & $16(13.6)$ & $11(11.1)$ \\
\hline \multicolumn{3}{|l|}{ Self-reported age at arrival, years } \\
\hline Mean (SD) & $67.3(7.8)$ & $68.3(6.7)$ \\
\hline Median (IQR) & $65(10)$ & $67(8)$ \\
\hline Maximum & 101 & 88 \\
\hline
\end{tabular}

$\mathrm{SD}$, standard deviation; IQR, interquartile range. ${ }^{a}$ Due to rounding, column percentages may not add up to $100 \%$. ${ }^{\mathrm{b}}$ Countries/ethnicities with $<5$ total arrivals during the study period, in order of magnitude, were: Burma (4), Karenni (4), Eritrea (3), Kachin (2), Russia (2), Syria (2), Burundi (1), China (1), Ethiopia (1), Mon (1), Nepal (1), Palestine (1), Rohingya (1), Rwanda (1), South Sudan (1), and Somali Bantu (1), with 0 individuals of unknown origin.

woman doing so. Urinary tract infections, along with a history of failure to thrive, affected only the women in the analysis ( 2 individuals each), whereas only men reported the loss of a limb $(n=2)$, macrocytic anemia $(n=1)$, scabies $(n=2)$, and tinea $(n=1)$.

\section{Discussion}

Diseases correlated with increasing age, such as hypertension, decreases in vision, arthritis, and low back pain, were also common among our study population of refugees aged 60 years and older. Remediation for some of the ailments, such as decreased visual acuity, may only require 1 visit to a practitioner (e.g., fitting for eye glasses). Health-care providers can, therefore, easily test for and correct these conditions in a single visit.

Much of what afflicts this population, however, requires longer-term care and multiple follow-up visits, 
Table 2. Positive diagnoses of refugee men and women aged 60 years and older arriving in Utah between 2012 and 2017 by specialty area

\begin{tabular}{|c|c|c|c|}
\hline \multirow[t]{2}{*}{ Diagnosis by specialty area } & \multicolumn{3}{|c|}{ Individuals with a positive diagnosis by gender } \\
\hline & $\begin{array}{l}\text { both } \\
(n=217)\end{array}$ & $\begin{array}{l}\text { men } \\
(n=118)\end{array}$ & $\begin{array}{l}\text { women } \\
(n=99)\end{array}$ \\
\hline Any positive diagnosis, $n(\%)^{\mathrm{a}}$ & $198(91.2)$ & $107(90.7)$ & $91(91.9)$ \\
\hline Cardiology, $n(\%)$ & $96(44.24)$ & $53(44.9)$ & $43(43.4)$ \\
\hline Elevated BP without hypertension diagnosis & $25(11.5)$ & $15(12.7)$ & $10(10.1)$ \\
\hline Heart murmur & $3(1.4)$ & $1(0.8)$ & $2(2.0)$ \\
\hline Hypertension & $73(33.6)$ & $40(33.9)$ & $33(33.3)$ \\
\hline Dental, $n(\%)$ & $33(15.2)$ & $16(13.6)$ & $17(17.2)$ \\
\hline Calculus & $4(1.8)$ & $2(1.7)$ & $2(2.0)$ \\
\hline Caries & $16(7.4)$ & $8(6.8)$ & $8(8.1)$ \\
\hline Decay & $18(8.3)$ & $11(9.3)$ & $7(7.1)$ \\
\hline Pain & $10(4.6)$ & $5(4.2)$ & $5(5.1)$ \\
\hline Dermatology, $n(\%)$ & $6(2.8)$ & $3(2.5)$ & $3(3.0)$ \\
\hline Dermatitis & $5(2.3)$ & $2(1.7)$ & $3(3.0)$ \\
\hline Scabies & $2(0.9)$ & $2(1.7)$ & $0(0.0)$ \\
\hline Tinea & $1(0.5)$ & $1(0.5)$ & $0(0.0)$ \\
\hline Ear, nose, and throat, $n(\%)$ & $35(16.1)$ & $23(19.5)$ & $12(12.1)$ \\
\hline Hearing decreased & $18(8.3)$ & $10(8.5)$ & $8(8.1)$ \\
\hline Impacted cerumen & $20(9.2)$ & $13(11.0)$ & $7(7.1)$ \\
\hline Perforated tympanic membrane & $5(2.3)$ & $4(3.4)$ & $1(1.0)$ \\
\hline Tinnitus & $4(1.8)$ & $2(1.7)$ & $2(2.0)$ \\
\hline Endocrinology, $n(\%)$ & $32(14.8)$ & $17(14.4)$ & $15(15.2)$ \\
\hline Diabetes & $30(13.8)$ & $16(13.6)$ & $14(14.1)$ \\
\hline Thyroid disorders & $3(1.4)$ & $1(0.8)$ & $2(2.0)$ \\
\hline Gastroenterology, $n(\%)$ & $38(17.5)$ & $16(13.6)$ & $22(22.2)$ \\
\hline Abdominal pain & $28(12.9)$ & $11(9.3)$ & $17(17.2)$ \\
\hline Constipation & $17(7.4)$ & $11(9.3)$ & $6(6.1)$ \\
\hline Diarrhea & $4(1.8)$ & $2(1.7)$ & $2(2.0)$ \\
\hline Hematology, $n(\%)$ & $8(3.7)$ & $4(3.4)$ & $4(4.0)$ \\
\hline Eosinophilia & $5(2.3)$ & $2(1.7)$ & $3(3.0)$ \\
\hline Macrocytic anemia & $1(0.5)$ & $1(0.8)$ & $0(0.0)$ \\
\hline Microcytic anemia & $2(0.9)$ & $1(0.8)$ & $1(1.0)$ \\
\hline Infectious diseases, $n(\%)$ & $93(42.9)$ & $55(46.6)$ & $38(38.4)$ \\
\hline Hepatitis B & $4(1.8)$ & $2(1.7)$ & $2(2.0)$ \\
\hline Hepatitis $\mathrm{C}^{\mathrm{b}}$ & $6(2.8)$ & $3(6.7)$ & $3(6.5)$ \\
\hline HIV & $0(0.0)$ & $0(0.0)$ & $0(0.0)$ \\
\hline Parasites & $3(1.4)$ & $1(0.8)$ & $2(2.0)$ \\
\hline Sexually transmitted infections & $4(1.8)$ & $3(2.5)$ & $1(1.0)$ \\
\hline Tuberculosis & $85(39.2)$ & $50(42.4)$ & $35(35.4)$ \\
\hline Musculoskeletal, $n(\%)$ & $59(27.2)$ & $25(21.2)^{*}$ & $34(34.3)^{*}$ \\
\hline Arthritis & $27(12.4)$ & $11(9.3)$ & $16(16.2)$ \\
\hline Loss of limb & $2(0.9)$ & $2(1.7)$ & $0(0.0)$ \\
\hline Low back pain & $33(15.2)$ & $13(11.0)$ & $20(20.2)$ \\
\hline Musculoskeletal pain & $11(5.1)$ & $3(2.5)$ & $8(8.1)$ \\
\hline Neurology, $n(\%)$ & $19(8.8)$ & $13(11.0)$ & $6(6.1)$ \\
\hline Headaches & $16(7.4)$ & $11(9.3)$ & $5(5.1)$ \\
\hline Neuropathy & $5(2.3)$ & $4(3.4)$ & $1(1.0)$ \\
\hline Seizures & $2(0.9)$ & $1(0.8)$ & $1(1.0)$ \\
\hline
\end{tabular}


Table 2 (continued)

\begin{tabular}{lccc}
\hline Diagnosis by specialty area & \multicolumn{2}{l}{ Individuals with a positive diagnosis by gender } \\
\cline { 2 - 4 } & $\begin{array}{l}\text { both } \\
(n=217)\end{array}$ & $\begin{array}{c}\text { men } \\
(n=118)\end{array}$ & $\begin{array}{c}\text { women } \\
(n=99)\end{array}$ \\
\hline Nutrition, $n(\%)$ & $9(4.2)$ & $4(3.4)$ & $5(5.1)$ \\
Failure to thrive & $2(0.9)$ & $0(0.0)$ & $2(2.0)$ \\
Malnutrition & $8(3.7)$ & $4(3.4)$ & $4(4.0)$ \\
\hline Ophthalmology, $n(\%)$ & $136(62.7)$ & $71(60.2)$ & $65(65.7)$ \\
Corneal opacity & $15(6.9)$ & $10(8.5)$ & $5(5.0)$ \\
Visual acuity $>20 / 40$ & $97(44.7)$ & $52(44.1)$ & $45(45.5)$ \\
Vision decreased & $86(39.6)$ & $42(35.6)$ & $44(44.4)$ \\
\hline Psychology, $n(\%)$ & $59(27.2)$ & $31(26.3)$ & $28(28.3)$ \\
Anxiety & $18(8.3)$ & $7(5.9)$ & $11(11.1)$ \\
Depression & $23(10.6)$ & $10(8.5)$ & $13(13.1)$ \\
RHS-I & $88(40.6)$ & $43(36.4)$ & $45(45.5)$ \\
RHS-II & $50(23.0)$ & $26(22.0)$ & $24(24.2)$ \\
Torture/violence & $21(9.7)$ & $16(13.6)^{*}$ & $5(5.1)^{*}$ \\
\hline Pulmonology, $n$ (\%) & $26(12.0)$ & $18(15.3)$ & $8(8.1)$ \\
Asthma & $7(3.2)$ & $4(3.4)$ & $3(3.0)$ \\
Chronic obstructive pulmonary disorder & $6(2.8)$ & $4(3.4)$ & $2(2.0)$ \\
Tobacco use & $7(3.2)$ & $6(5.1)$ & $1(1.0)$ \\
\hline Urology, $n$ (\%) & $16(7.4)$ & $10(8.5)$ & $6(6.1)$ \\
Dysuria & $10(4.6)$ & $7(5.9)$ & $3(3.1)$ \\
Nocturia & $6(2.8)$ & $5(4.2)$ & $1(1.0)$ \\
Urinary tract infection & $2(0.9)$ & $0(0.0)$ & $2(2.0)$ \\
\hline
\end{tabular}

BP, blood pressure. ${ }^{\mathrm{a}}$ Percentages are referenced to each column total $(n) .{ }^{\mathrm{b}}$ Due to data collection methodology, the denominator for hepatitis $\mathrm{C}$ is men $(n=45)$ and women $(n=46){ }^{*} p>0.05$.

e.g., chronic diseases - such as hypertension, arthritis, and low back pain. It is not a surprise that the frequently reported condition of hypertension may underlie many of the other health complaints. For example, (1) hypertension, often without appreciable complaints by the patient, contributes to eye disease, including visual disturbances; (2) kidney disease; and (3) some evidence suggests a link between certain forms of arthritis and hypertension [19-21]. Anxiety and depression have also been reported to be a consequence of the diagnosis of hypertension and may contribute to noncompliance with antihypertensive medication adherence [22]. Complications of these chronic diseases are shown to decrease quality of life and increase mortality rates $[23,24]$. Thus, it is of critical importance that receiving communities are well acquainted with the needs of geriatric refugees suffering from chronic conditions requiring long-term care, and that access to quality health care should be a primary objective for those organizations serving them.

Determining Physical and Mental Health Conditions in Older Adult Refugees
Both acute and chronic conditions can be addressed and managed by health-care providers. However, many conditions may not be perceived as immediately life threatening, yet if left untreated, those conditions impede a refugee's ability to integrate into their resettlement community and can impact quality of life and longevity $[23,24]$. Hearing and vision loss, for example, can impair one's ability to learn a new language, which may in turn affect an individual's ability to find, or advance in, a job. Similarly, musculoskeletal conditions may impact mobility, thus affecting access to health care, the search for employment, or participation in other daily activities.

Excepting latent tuberculosis infection (LTBI; prevalence of $39.2 \%$ ), infectious disease has a limited role in our study population. The CDC had identified Priority Health Conditions for several refugee groups [25]. In response, the overseas screening program actively evaluates for and treats specific infectious conditions, such as certain parasitic infections, malaria, hepatitis, and diarrheal diseases. 
Thus, our data do not show a high prevalence of these conditions upon arrival, while showing a high prevalence of LTBI, as the CDC screens, evaluates, and treats only active tuberculosis in the overseas setting.

Most of the health conditions assessed in the RHSF affect women and men with a similar prevalence. Some notable exceptions are a history of torture and violence, and a propensity for tobacco use. When dealing with refugee men older than 60 years, providers should consider the psychological ramifications of having endured such atrocities, as well as introduction to evidence-based tobacco cessation programs. When working with refugee women of the same age, an increase in the prevalence of musculoskeletal pain and urinary tract infections should be considered.

It is also important to note that nearly every individual within this population (91\%) arrived with at least 1 preexisting condition. The high prevalence of these conditions within the geriatric population of refugees, along with their lack of familiarity with our health-care system, necessitates a creative approach to providing health and health care. Future research is needed to assess the prevalence of health conditions in younger age groups to determine how health education and care should be tailored for them. Replicating these findings within different states will also help elucidate the seeming discrepancies between our data and those of the CDC, while aiding in our understanding of their universality.

\section{Conclusion}

With the rise of international conflict, health-care providers in receiving countries must be prepared to meet the needs of a growing refugee population. The vast majority of refugees aged 60 years and older arrive with a health condition that requires care. Our findings suggest that older refugees are likely to arrive with diagnoses of LTBI, hypertension, vision impairment, musculoskeletal pain, and anxiety/depression/PTSD. Addressing these healthcare needs will prevent the accumulation of additional comorbid conditions, improve daily functionality, and is a critical step towards aiding refugees to achieve integration following resettlement.

\section{Acknowledgment}

We want to thank the Utah Department of Health for providing the data for analyses. A special thank you to Amelia Self for being willing to share the information and staff time for this study.

\section{References}

1 United Nations High Commissioner for Refugees (UNHCR): Figures at a glance, 2017. http://www.unhcr.org/en-us/figures-at-aglance.html.

2 Oberoi P, Sotomayor J, Pace P, Rijks B, Weekers J, Walilegene T: International Migration, Health and Human Rights. Geneva, International Organization for Migration, 2013.

3 US Department of Health and Human Services, Office of Refugee Resettlement: The Refugee Act, INA: ACT 411 - Office of Refugee Resettlement, Sec. 411. [8 U.S.C. 1521], 2012. https://www.acf.hhs.gov/orr/resource/ the-refugee-act.

4 Utah's Public Health Data Resource, Public Health Indicator Based Information System (IBIS): Health indicator report of refugee arrivals, 2018. https://ibis.health.utah.gov/indicator/view/RefArr.Year.html.

5 Morris MD, Popper ST, Rodwell TC, Brodine SK, Brouwer KC: Healthcare barriers of refugees post-resettlement. J Community Health 2009;34:529-538.

6 Deacon Z, Sullivan C: Responding to the complex and gendered needs of refugee women. Affilia 2009;24:272-284.
7 Kirmayer LJ, Narasiah L, Munoz M, Rashid M, Ryder AG, Guzder J, Hassan G, Rousseau C, Pottie K: Common mental health problems in immigrants and refugees: general approach in primary care. CMAJ 2011;183:E959-E967.

8 United Nations High Commissioner for Refugees (UNHCR): Safeguarding individuals: women, 2017. http://www.unhcr.org/en-us/ women.html.

9 Social Services Appropriation Subcommittee: Refugee assistance. Utah State Legislature, 2016. https://le.utah.gov/interim/2015/ pdf/00005565.pdf.

10 United Nations High Commissioner for Refugees (UNHCR): Age, Gender and Diversity. Accountability Report 2015. http://www.unhcr.org/protection/women/5769092c7/unhcr-age-gender-diversity-accountability-report-2015.html.

11 Patterson FM: Policy and practice implications from the lives of aging international migrant women. Int Soc Work 2004;47:25-37.

12 Shannon PJ, Wieling E, Simmelink-McCleary J, Becher E: Beyond stigma: barriers to discussing mental health in refugee populations. J Loss Trauma 2015;20:281-296.
13 Mollica RF, Wyshak G, Lavelle J: The psychosocial impact of war trauma and torture on Southeast Asian refugees. Am J Psychiatry 1987;144:1567-1572.

14 Westermeyer J: DSM-III psychiatric disorders among Hmong refugees in the United States: a point prevalence study. Am J Psychiatry $1988 ; 145 ; 197-202$.

15 Kinzie JD, Boehnlein JK, Leung PK, Moore L, Riley C, Smith D: The prevalence of posttraumatic stress disorder and its clinical significance in Southeast Asian refugees. Am J Psychiatry 1990;147:913-918.

16 Ito KL, Chung RC, Kagawa-Singer M: Asian/ Pacific American women and cultural diversity: studies of the traumas of cancer and war; in Ruzek SB, Olesen VL, Clarke A (eds): Women's Health: Complexities and Differences. Columbus, OH, Ohio State University Press, 1997, pp 300-328.

17 Centers for Disease Control and Prevention: Travelers health: advising travelers with specific needs, 2017. https://wwwnc.cdc.gov/ travel/yellowbook/2018/advising-travelerswith-specific-needs/newly-arrived-immigrants-refugees. 
18 Hollifield M, Verbillis-Kolp S, Farmer B, Toolson EC, Woldehaimanot T, Yamazaki J, Holland A, St Clair J, SooHoo J: The Refugee Health Screener-15 (RHS-15): development and validation of an instrument for anxiety, depression, and PTSD in refugees. Gen Hosp Psychiatry 2013;35:202-209.

19 Solomon DH, Curhan GC, Rimm EB, Cannuscio CC, Karlson EW: Cardiovascular risk factors in women with and without rheumatoid arthritis. Arthritis Rheum 2004;50:34443449.
20 Solomon DH, Karlson EW, Rimm EB, Cannuscio CC, Mandl LA, Manson JE, Stampfer MJ, Curhan GC: Cardiovascular morbidity and mortality in women diagnosed with rheumatoid arthritis. Circulation 2003;107:13031307.

21 Wallberg-Jonsson S, Ohman ML, Dahlqvist SR: Cardiovascular morbidity and mortality in patients with seropositive rheumatoid arthritis in Northern Sweden. J Rheumatol 1997;24:445-451.

22 Alcántara C, Edmondson D, Moise N, Oyola D, Hitilan D, Kronish M: Anxiety sensitivity and medication nonadherence in patients with uncontrolled hypertension. J Psychosom Res 2014;77:283-286.
23 Muhtz C, Godemann K, Von Alm C, Wittekind C, Goemann C, Wiedemann K, Yassouridis A, Kellner M: Effects of chronic posttraumatic stress disorder on metabolic risk, quality of life, and stress hormones in aging former refugee children. J Nerv Ment Dis 2011;199:646-652.

24 Wei MY, Kawachi I, Okereke OI, Mukamal $\mathrm{KJ}$ : Diverse cumulative impact of chronic diseases on physical health related quality of life: implications for a measure of multimorbidity. Am J Epidemiol 2016;184:357-365.

25 Centers for Disease Control and Prevention, Refugee Health Profiles: Refugee Health Profiles, 2017. https://www.cdc.gov/immigrantrefugeehealth/profiles/index.html. 